\title{
LOTUS, WHITE CLOVER AND CAUCASION CLOVER OVERSOWING, MESOPOTAMIA STATION, SOUTH CANTERBURY
}

\author{
R. J. Lucas, J. G. H. White, G. T. daly, P. Jarvis and \\ G. MEIJER
}

Plant Science Department, Lincoln College, Canterbury

\begin{abstract}
Results from a legume oversowing and phosphorus topdressing experiment are reported. The depleted tussock grassland site at $700 \mathrm{~m}$ altitude with $1000 \mathrm{~mm}$ rainfall, soil $\mathrm{pH}$ of 5.25 and low available $\mathrm{P}$ plus Hieracium weed invasion was typical of much South Island montane grazing land.

'Grasslands Maku' lotus (Lotus pedunculatus Cav.) and 'Grasslands Huia' white clover (Trifolium repens L.) established rapidly and yields in the second year were similar but lotus gave higher yields subsequently. White clover had lower p\% in leaf dry matter and higher scarab populations than lotus. Trifolium umbiguum $\mathrm{cv}$. Prairie establishment was sparse and yields were low at first but after five years it had spread by rhizome growth to form a moderately productive sward.

All legume species responded to increasing rates of $\mathrm{P}$ at establishment and to greater frequency of maintenance superphosphate but the most efficient superphosphate regime was for low to moderate rates (123 to $300 \mathrm{~kg} / \mathrm{ha}$ ) at sowing reinforced by annual topdressings at $125 \mathrm{~kg} / \mathrm{ha}$. Legume oversowing with fertilizer substantially reduced Hieracium pilosella cover.
\end{abstract}

\section{INTRODUCTION}

As large amounts of fertilizer and lime are required for the establishment and maintenance of white clover-based pastures on acid, infertile soils, efforts are being made to find better adapted legumes which need less fertilizer and lime. This search has become more urgent with the rapidly increasing cost of applying fertilizer. High country farmers are particularly interested in low-cost legume oversowing and topdressing to combat the loss of grazing caused by mouse-ear hawkweed (Hieracium pilosella) invasion.

'Grasslands Maku' lotus (Lotus pedunculatus Cav.) and Caucasian clover (Trifolium ambiguum Bieb.) cv. Prairie are two 
legumes which may be better adapted to some montane environments than white clover. Lowther (1980) showed that Maku lotus was higher yielding than white clover when over-sown on a low fertility tussock grassland soil, $\mathrm{pH} 4.6$ to 4.8. The lotus responded strongly to increasing phosphate but white clover was inhibited by soil acidity. Caucasian clover is a strongly perennial, rhizomatous legume which is well adapted to cool continental climates. Once established, the substantial root reserves of Caucasian clover enable it to survive close grazing and dry summers. The hexaploid T. ambiguum cv. Prairie is an Australian cultivar which was developed for revegetation of eroded soils in the Snowy Mountains of New South Wales (Anon., 1977).

This paper presents results from the first five years of a continuing fertilizer and legume species trial at Mesopotamia Station, Rangitata Valley, South Canterbury. Maku lotus and Prairie Caucasian clover were compared with 'Grasslands Huia' white clover (Trifolium repens L.) for oversowing montane tussock grassland at a wide range of establishment phosphorus rates. Three frequencies of maintenance phosphorus fertilizer applications were studied because phosphorus-efficient legumes may be able to produce well without annual topdressing. Observation of the effect of the legume and phosphorus treatments on Hieracium spp. was also an experimental aim.

\section{EXPERIMENTAL}

The trial site is situated on the extensive terrace country of Mesopotamia Station at an altitude of $700 \mathrm{~m}$ and with a mean annual rainfall of $1000 \mathrm{~mm}$. The soil is an upland yellow-brown earth in the Cass soil set with topsoil $\mathrm{pH}$ range from 4.9 to 5.5. Available phosphorus is low, with Olsen $P$ values of 3 to 10 . The sparse vegetation cover in September 1975 consisted chiefly of browntop, sweet vernal, $\mathrm{H}$. pilosella $(15 \%)$, sorrel, and plant litter with scattered fescue and snow tussocks. The area had been grazed by sheep and the inter-tussock vegetation was short and open after winter frosts.

The trial was laid down on 4 September 1975 and deer-fenced soon after. Initially a factorial randomized block design with three replicates was used, Inoculated, lime-pelleted seed of each of the three legumes was oversown at $4 \mathrm{~kg}$ seed/ha with $10,25,50$ or $100 \mathrm{~kg} \mathrm{P} / \mathrm{ha}$ applied as triple superphosphate. Basal sulphur and molybdenum were applied to all plots as gypsum (30 kg S/ha) and $175 \mathrm{~g} / \mathrm{ha}$ sodium molybdate. Additional basal gypsum (30 $\mathrm{kg} \mathrm{S} / \mathrm{ha}$ ) was applied in 1978. 
The thirty-six $20 \mathrm{~m} \mathrm{X} 5 \mathrm{~m}$ main plots were each split into three sub-plots in September 1976 when the frequency of maintenance phosphorus treatments were started. Superphosphate was applied at $125 \mathrm{~kg} / \mathrm{ha}$ either annually, every two years or not at all.

Plots were not grazed in the first growing season (1975-6) but in subsequent years the trial area was grazed hard by sheep after each early summer harvest and grazed again in late summer or autumn.

Plots were visually assessed three or four times per year but harvests of spring growth only were possible in the 3 seasons 1976-1979, and three cuts were taken in the $1979-80$ season. Plots were sampled for dry matter yield by taking $3 \times 0.33 \mathrm{~m}^{2}$ cuts with a hedge trimmer from each sub-plot. Botanical composition was assessed by point analysis in September 1975 and May 1980 and by botanical dissection of samples after each yield cut with the exception of the 1976-7 harvest. Nutrient analyses were done on grass and legume samples plucked separately in the field. Turf was sampled for scarab larvae in May 1978, November 1978, and April 1980.

\section{RESULTS}

\section{ESTABLISHMENT}

A dense population of white clover germinated and established. Lotus establishment was satisfactory but with a much lower plant density than in white clover. Trifolum ambiguum establishment from oversowing was sparse, with only 4.5 plants per $\mathrm{m}^{2}$.

In general, seedlings established well on bare ground, plant litter or vegetated areas with the exception of $\mathrm{Hieracium} \mathrm{pilosella}$ patches where few legume seedlings survived. Visual assessment of cover in October 1976, thirteen months after sowing, showed a positive response to increasing establishment phosphorus. Mean cover estimates from all phosphate treatments for white clover, lotus and $T$. ambiguum were 58, 46 and 10\%, respectively.

\section{Dry Matter Yieids: Legume Species EFFects}

Total dry matter yields from spring harvests for the three legume treatments averaged over all phosphate rates are shown in Table 1. Lotus and white clover total yields were similar in all seasons except in the third spring (1977) when lotus mean total yield was $30 \%$ higher than white clover. Trifolium ambiguum total yields were very low in the second spring but approached those of the other two legumes by 1979 . 
TABLE 1: TOTAL YIELDS FROM SPRING HARVESTS (kg/ha)

\begin{tabular}{lcccc}
\hline & \multicolumn{4}{c}{ Harvest Date } \\
& 25.12 .76 & 1212.77 & 6.12 .78 & 26.11 .79 \\
\hline Lotus & 2520 & 3240 & 2160 & 2460 \\
White clover & 2570 & 2470 & 1860 & 2280 \\
T. ambiguum & 180 & 1700 & 900 & 2040 \\
SEM & & 150 & 90 & 150 \\
\hline
\end{tabular}

The contribution of the legumes to these total yields is shown in Table 2. Lotus production was about $40 \%$ higher than white clover herbage yields in all spring cuts except 1976 when both white clover and lotus plots were legume-dominant and botanical separation was not done.

TABLE 2: LEGUME YIELDS AND LEGUME \% OF TOTAL YIELD FROM SPRING HARVESTS $(\mathrm{kg} / \mathrm{ha}$ and $(\%)$ )

\begin{tabular}{lccr}
\hline & & Harvest Date & \\
& 12.12 .77 & 6.12 .78 & 26.11 .79 \\
\hline Lotus & $1550(50)$ & $1050(47)$ & $1570(63)$ \\
White clover & $1180(46)$ & $640(35)$ & $1030(45)$ \\
T. ambiguum & $650(36)$ & $440(43)$ & $1380(64)$ \\
SEM & $70(2)$ & $55(2)$ & $90(2)$ \\
\hline
\end{tabular}

The percentage legume means show that lotus was. a major contributor to total yield in all spring cuts while white clover as a percentage of its total yield declined over time relative to lotus. Legume yields from T. ambiguum plots have increased with time but volunteer white clover in these plots has been partly responsible for the increasing proportion of legume with successive seasons. Forty percent of the 1979 spring legume yield in T. ambiguum plots was white clover. Lotus plots were also invaded by white clover and for the three cuts taken during the 1979-80 season $15 \%$ of the total legume yield in the lotus plots was white clover.

\section{EFFETS OF Phosphorus}

Increasing rates of phosphorus at establishment $(\mathrm{Pe})$ and increasing frequency of maintenance phosphorus $(\mathrm{Pm})$ resulted in large increases in total and legume yields. The influence of Pe diminished with time and the effect of Pm became relatively more 


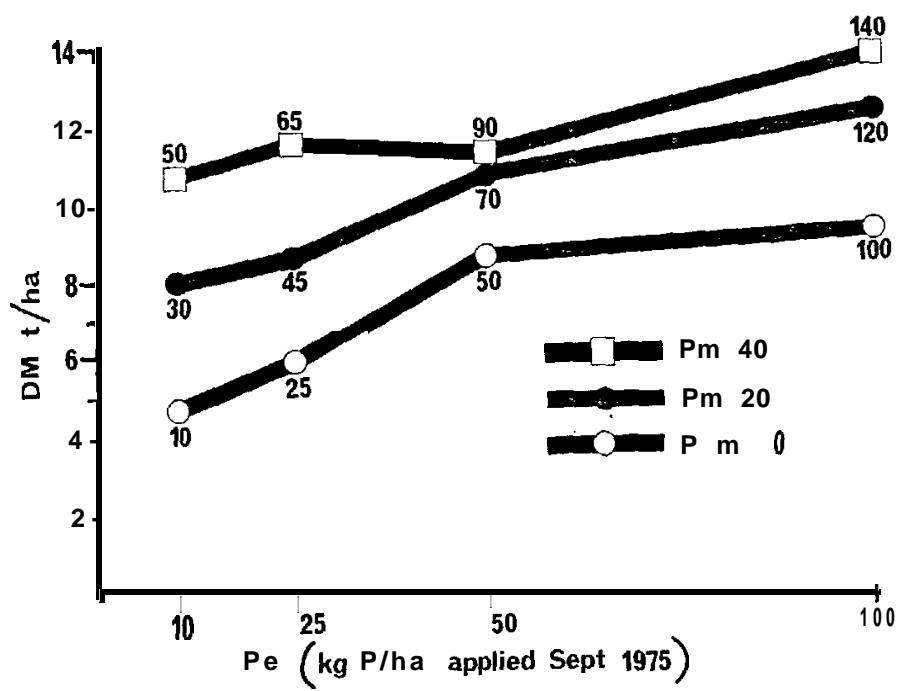

FIg. 1: The effects of establishment $P(P e)$ rates and maintenance $P(P m)$ frequency on sum of total $D M$ from spring, 1977, 197.8 and 1979, plus summer and autumn 1980. Total $\mathrm{kg}$ of $\mathrm{P}$ applied are shown near plotted mean yields. $\left(P e \times \mathrm{Pm}^{* *}\right.$; SEM : Pe 0.5, Pm 0.2)

important. Figure 1 shows the sum of total yields over three years plotted against Pe for different levels of maintenance P. Dry matter responses per unit of phosphorus applied were best where moderate to low rates of Pe were supplemented by regular Pm.

\section{LEGUME $\mathbf{X}$ PhosphoRus INTERACTIONS}

In general, the phosphorus response curves of the legume species were similar, with lotus normally highest yielding. Where the interactions were significantly different, it was often caused by the low population and poor performance of $T$. ambiguum rather than differences in response patterns between white clover and lotus.

Figure 2 illustrates a species x Pm interaction where 1979-80 sown legume response curves of white clover and lotus were similar but T. ambiguum was less responsive. It should be noted, however, that lotus was $82 \%$ better than white clover without maintenance $\mathrm{P}$ but was only $15 \%$ better with annual phosphorus.

Grass yields were generally highest in white clover plots after the third season. This was particuarly so at higher P levels. Figure 3 illustrates the legume species x Pe interaction for 1978 grass 


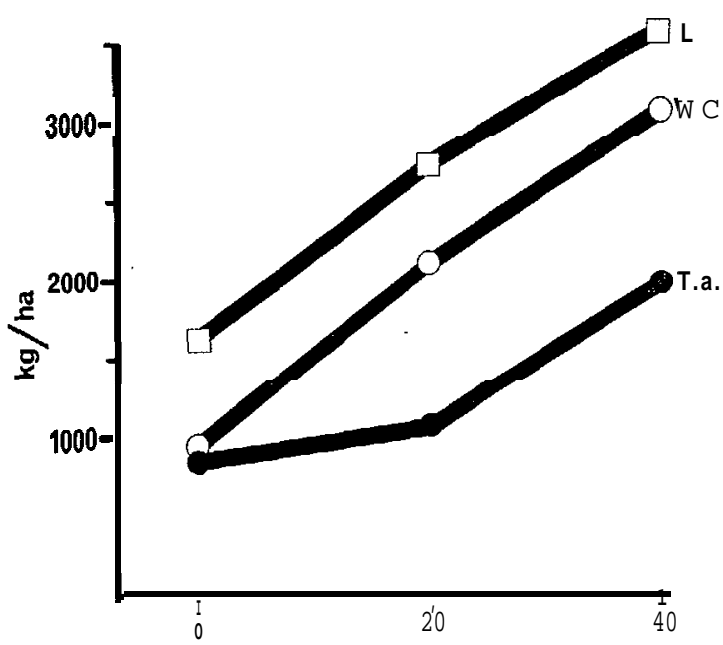

Pm kg P/ha over 4 years

FIG. 2: The effects of maintenance $P$ level on sow $n$ legume DM 1979-80 (Spp $\mathrm{x}$ Pm**). (WC Huia white clover; L Maku lotus; T.a. Trifolium ambiguum)

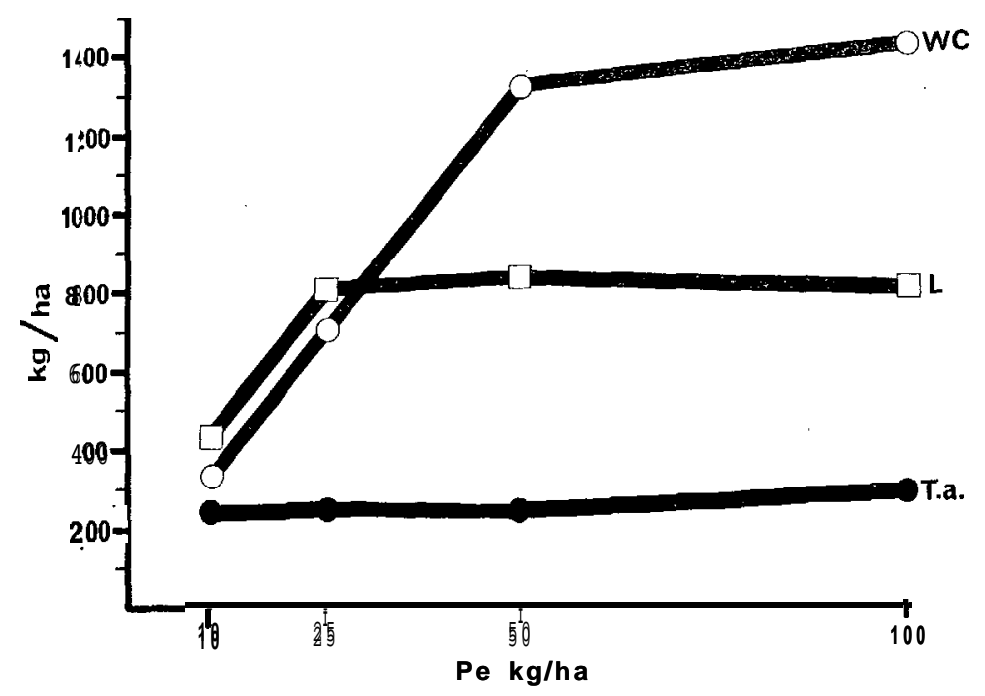

FIg. 3: The effects of establishment $P$ rate and legume species on grass DM 1978 (SPP. x Pe***). (WC Huia white clover; L Maku lotus; T.a. Trifolium ambiguum plots). 
yields from the three legume treatments. Grass growth did not benefit from T. ambiguum oversowing, grass in lotus plots was responsive up to $25 \mathrm{~kg} / \mathrm{ha}$ of $\mathrm{Pe}$, while grass growing with white clover increased up to the $50 \mathrm{~kg} / \mathrm{ha}$ level of Pe.

\section{Chemical Composition}

Mean $\% \mathrm{~N}$ and $\% \mathrm{P}$ in grass and legume herbage are presented in Table 3. Nitrogen level of the grass growing with clover was significantly higher than $\% \mathrm{~N}$ of grass associated with lotus. There were no differences in mean $\% \mathrm{P}$ between grass samples from the three legume treatments. White clover $\% \mathrm{P}$ was significantly lower than lotus \% P in 1977 and 1978. Lotus nitrogen level was greater than in white clover in 1977 but with higher levels of P in 1978 the $\% \mathrm{~N}$ also increased and differences between the legumes were reduced.

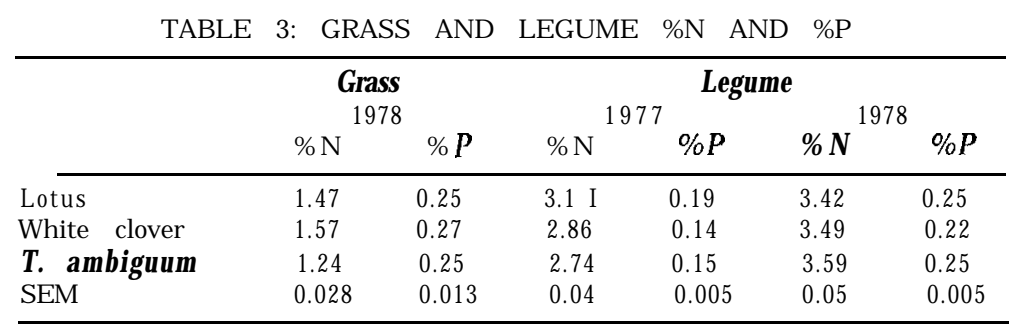

SCARAB NUMBERS

Table 4 shows mean scarab larvae numbers $/ \mathrm{m}^{2}$ of turf on three sample dates. T. ambiguum plots were not sampled because of white clover contamination. The most common scarab species present was the common grass grub (Costelytra zelandica).

TABLE 4: SCARAB LARVAE (NUMBER/m*)

\begin{tabular}{lccr}
\hline & $19 / 5 / 78$ & $26 / 11 / 79$ & $21 / 4 / 80$ \\
\hline Lotus & 40 & 85 & 130 \\
SEM & 9 & 20 & 33 \\
White clover & 120 & 270 & 250 \\
SEM & 48 & 83 & 57 \\
\hline
\end{tabular}

White clover plots had much higher scarab populations than lotus plots but the difference appears to be decreasing with time. This may be due partly to white clover invasion of lotus plots. 


\section{H IERACIUM}

Point analysis in May 1980 showed that legume oversowing and phosphorus fertilization will suppress $\mathrm{H}$. pilosella. Annual maintenance $\mathrm{P}$ reduced the weed cover to $4 \%$ while no maintenance $\mathrm{P}$ reduced weed cover to $8 \%$ at $25 \mathrm{~kg} / \mathrm{ha} \mathrm{Pe}$ and above but it was not changed from the original September 1975 level of $15 \%$ at Pe of $10 \mathrm{~kg} / \mathrm{ha}$. The two heavy grazings per year, in the absence of legume oversowing and phosphorus fertilization, increased H. pilosella to $29 \%$ ground cover.

\section{DISCUSSION}

In a number of trials Nordmeyer and Davis (1977), Lowther (1977, 1980), and Scott and Mills (1981) have shown the superiority of $L$. pedunculatus over white clover on acid soils, low in available P. The present trial area had a soil pH of 5.25 and 1otus outyielded white clover by only $40 \%$. This is consistent with the results of Scott and Mills (1981) who show that lotus is favoured as soil $\mathrm{pH}$ falls below 5.2.

A legume succession may be developing in this ldng-term trial at Mesopotamia. Initially, white clover equalled lotus production but has since declined. Lotus 'production has been maintained similar to the results of Scott and Mills (1981) who demonstrated that Maku lotus has good persistence under both sheep and cattle grazing in Otago acid tussock grasslands. However, there is some doubt about its persistence under intensive grazing on fertile soil of higher $\mathrm{pH}$ (Brock and Charlton, 1978). Trifolium ambiguum is increasing its large underground reserves and steadily improving in herbage production. Bryant (1974) has reviewed Australian experience with T. ambiguum and emphasizes its longterm persistence in soils of low $\mathrm{P}$ status under uncontrolled sheep grazing. After recovering from sparse establishment, T. ambiguum in the Cass soil at Mesopotamia could provide a permanent legume component while the other two species fluctuate with the vagaries of grazing management, summer drought and grass grub attack.

The decline in yield of white clover relative to lotus is not entirely due to tolerance of soil acidity and phosphate efficiency in the latter species. Greater vigour and higher $\% \mathrm{~N}$ of grasses associated with white clover suggest that white clover roots and litter hreak down and release nitrogen to associated grasses faster than do those of lotus. Earlier work by Brock (1973) led to a similar conclusion. White clover then suffers more grass competition while lotus retains its nitrogen longer, so restricting the growth 
of resident grasses. Long, lax stems of lotus are thus able to compete strongly for light against weaker grass growth. In addition, -"he resistance of lotus to grass grub attack, together with a deeper rooting habit, also confer advantages over white clover during dry rummers.

White clover has some advantages over lotus in marginally acidic soils ( $\mathrm{pH} 5.2$ to 5.4). Grazing management can be flexible because white clover will tolerate set-stocking. White clover seed is much cheaper than that of lotus and is likely to remain so. Add to this the greater ease with which white clover establishes from oversowing, earlier spring growth and free-seeding nature, allowing stock to spread the seed in the dung. Because of such features, the temptation will remain for farmers to include white clover with lotus in seed mixtures when oversowing. The aggressiveness of white clover seedlings makes it unwise to mix the two legumes on soils above pH 5.2 while Lowther (1980) has shown that a mixture is less productive than lotus alone in more acid soils.

Although Prairie Caucasian clover is showing promise at Mesopotamia as a verv persistent grazing- and drought-tolerant legume, we have little evidence of its suggested phosphate efficiency so far. The lack of commercial quantities of seed and its poor establishment when oversown will restrict its use in the near future, but further experimentation with Prairie and other Caucasian clover varieties appears to be justified.

The generallv recommended fertilizer rates for oversowing and topdressing tussock country of 125 to $300 \mathrm{~kg}$ superphosphate at establishment and annual or biennial maintenance rates of 125 $\mathrm{kg} / \mathrm{ha}$ were confirmed in the Mesonotamia experiment. There was no advantage in high initial establishment rates with no maintenance fertilizer.

The sunpression of $H$. pilosella at low to moderate rates of fertilizer with legume oversowing demonstrated a positive approach which can be used against the weed in these medium rainfall tussock grasslands. The economics of high country development will determine the extent to which this strategy is adopted.

\section{ACKNOWLEDGEMENTS}

We gratefully acknowledge the considerable help and continuing interest of Malcolm Prouting and his family at Mesopotamia. Thanks are also due to Dr David Penman for permission to use his scarab data and to K. K. Kee for his chemical analysis data. We also wish to thank other members of the Plant Science Depart- 
ment, Lincoln College, for their contributions in the field, laboralory and with computing.

\section{REFERENCES}

Anon., 1977. J. Aust. Inst. agric. Sci., 43: 92-4.

Brock, J. L., 1973. N.Z. /l agric. Res., 16: 483-91

Brock, J. L.; Charlton, J. F. L., 1978. Proc. N.Z. Grassld A ss., 39: 121-9.

Bryant, W. G., 1974. J. Aust. Inst. agric. Sci., 40: 11-9.

Lowther, W. L., 1977. Proc. N.Z. Grassld A SS., 38: 133-9. 1980. N.Z. $/ l$ exp. A gric., 8: 131-S.

Nordmeyer, A. H.; Davis, M. R., 1977. Proc. N.Z. Grassld A ss., 38: 119-25.

Scott, R. S.; Mills, E. G., 1981. Proc. N.Z. Grassld A sS., 42: 131-41. 